\title{
Indices in differentiating iron deficiency anemia from thalassemia trait- a comparative study
}

\author{
Sufia Ahmad', Noorin Zaidi', Syed Riaz Mehdi ${ }^{3}$, Sumaiya Irfan ${ }^{4}$, Sharique Ahmad ${ }^{5}$ \\ ${ }^{1}$ Assistant Professor, Department of Pathology, Maharani Laxmi Bai Medical College, Jhansi, ${ }^{2}$ Associate Professor, \\ ${ }^{3,5}$ Professor, ${ }^{4}$ Assistant Professor, Department of Pathology, Eras Lucknow Medical College and Hospital, Lucknow
}

Background: Iron deficiency anemia (IDA) and beta thalassemia trait (BTT) are the two most common and important causes of microcytic hypochromic anemia in India. It is very difficult to differentiate between the two. Many different types of techniques have been proposed for the same. While some are invasive like bone marrow examination others are not available at all centers, like electrophoresis. Hence different indices come into play. Aims and Objective: This study was undertaken to compare the efficacy of Shine and Lal index and Mentzer index in differentiating between IDA and BTT. Materials and Methods: A total of 407 anemia cases were studied over a period of 18 months and their blood samples were subject to different hematological and biochemical assays to diagnose the type of anemia. Results: Based on these tests $92.1 \%$ cases were found to be of IDA whereas $3.7 \%$ cases were found to be of BTT. Then both the indices were applied in the above mentioned cases. Conclusion: While Shine and Lal index was found to have better sensitivity, Mentzer index was found to have better specificity.

Key words: Iron deficiency anemia; Beta thalassemia trait; Shine and Lal index; Mentzer index

\section{INTRODUCTION}

Anemia is a global public health problem affecting both developing and developed countries with major consequences for human health as well as social and economic development. It is the result of wide variety of causes that can be isolated, but more often co-exist. Globally, the most significant contributor to the onset of anemia is iron deficiency, so that Iron deficiency anemia (IDA) and Anemia are often used synonymously. It is generally assumed that $50 \%$ of the cases of anemia are due to Iron deficiency but the proportion may vary among population groups and in different geographical regions according to the local conditions. ${ }^{1,2}$

Morphologically, mirocytic anemias are among the most common type of anemias encountered by physicians and
Access this article online

Website:

http://nepjol.info/index.php/AJMS DOI: $10.3126 /$ ajms.v12i10.38268

E-ISSN: 2091-0576

P-ISSN: 2467-9100

Copyright (c) 2021 Asian Journal of Medical Sciences

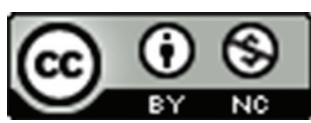

This work is licensed under a Creative Commons Attribution-NonCommercial 4.0 International License. 
worldwide. ${ }^{10}$ It is an autosomal hematological disorder resulting from genetically deficient synthesis of $\beta$-globin chain of $\mathrm{Hb}$ which leads to an excessive accumulation of $\alpha$ - globin chains. The extra $\alpha$-globin chain precipitates and forms inclusion bodies in RBCs, which may be apparent in mildest $\beta$-Thalassemia Trait (BTT). The BT'T patients are usually asymptomatic. They may present with mild anemia, headache or leg cramps. Peripheral blood smear shows same picture as IDA. ${ }^{11}$

It is important to differentiate between the IDA and BTT because each has entirely different etiology, pathogenesis, treatment and prognosis. Thus an unknown number of misdiagnosed thalassemia may be unnecessarily treated with iron. The real danger of misdiagnosed or non-diagnosis in carriers of BTT getting married, is a potential homozygous off spring.

In an era of rising cost consciousness, efficient diagnostic approaches which can rule in or out diseases with efficient accuracy so that testing is minimized, are welcome. Bone marrow studies are invasive methods and serum ferritin, serum transferrin and serum iron are relatively expensive tests, while $\mathrm{Hb}, \mathrm{RDW}$ along with other red cell indices are part of routine testing in laboratories using automated hematology analyzers. If these easily available tests could be used to screen IDA with acceptably high sensitivity and specificity, the cost of anemia workup would drop considerably. Hence, keeping the above discussion in mind the present study was carried out to segregate cases of pure BTT from IDA.

In the past, various indices have been proposed to discriminate IDA from BTT according to geographical variations. These discrimination indices proposed by different workers are derived from different hematological parameters. ${ }^{12}$

In this study, we have applied two indices; Shine and Lal index and Mentzer Index in

discriminating Iron Deficiency Anemia from Thalassemia Trait. The Shine and Lal Index, described in 1977, mentioned that in their three years of study on hemoglobinopathies, $\mathrm{HbA}_{2}$ was measured on 3734 samples, out of which 1973 cases were of microcytosis while 1761 were normocytic. The method of detecting and isolating BTT from IDA was carried out by applying the following newly derived formula based on red-blood cell indices.

Shine and Lal $(\mathrm{S} \& \mathrm{~L})$ Index $=(\mathrm{MCV} 2 \mathrm{X} \mathrm{MCH}) / 100$

The values of less than $<1530$ was indicative of BTT and of more than $>1530$ was suggestive of IDA. ${ }^{13}$
Mentzer index is calculated from the results of a CBC. If the quotient of MCV (in fl) divided by the RBC (in millions/microlitre) is less than 13 , thalassemia is said to be more likely. If the result is greater than 13, then IDA the possibility of IDA is higher. ${ }^{14,15} \mathrm{It}$ described in 1973 by Mentzer ${ }^{16}$ and is said to be helpful in differentiating IDA from beta thalassemia. ${ }^{17}$

\section{MATERIALS AND METHODS}

The present study was carried out for a period of 18 months at a tertiary care hospital in North India. An informed and written consent from subjects was taken before enrolling them. Initially all the cases with microcytic hypochromic anemia attending medicine and pediatric wards and outpatient departments (OPD) were screened for inclusion and exclusion criteria. Thus 407 cases of microcytic hypochromic anemia were enrolled for study. The inclusion and exclusion criterion were as follows:

\section{Inclusion criteria}

Patients having blood pictures of mild microcytic hypochromic anemia.

\section{Exclusion criteria}

- Previously diagnosed cases of thalassemia or any hemolytic anemia.

- Well investigated case of IDA on iron therapy.

- Transfusion dependent thalassemia major.

All the samples were run on Sysmex 800X I cell counter and complete blood counts (CBC) were obtained, which included total and differential leucocyte counts, platelet parameters, red blood cell counts, hemoglobin, red cell distribution width, mean corpuscular hemoglobin (MCH), mean corpuscular volume (MCV) and mean corpuscular hemoglobin concentration (MCHC). For microcytosis $\mathrm{MCV}<80$ and for hypochromia MCH $<27$ was taken as criterion.

After applying the discrimination indices, the suspected samples of IDA were confirmed by Serum ferritin (ELISA method), Serum Iron (Ferrozine method), TIBC (Ferrozine method) Those which were suspected to be BT'T were confirmed through cellulose acetate hemoglobin electrophoresis at alkaline $\mathrm{pH}$ of 8.6 on cellulose acetate strips, at $450 \mathrm{~V}$ for 1 hour and 15 minutes.

\section{Statistical analysis}

The statistical analysis was done using SPSS (Statistical Package for Social Sciences) Version 15.0 Statistical Analysis Software. The values were represented in Number $(\%) \&$ Mean \pm SD. 


\section{RESULTS}

As previously discussed, a total of 407 clinically suspected subjects were enrolled in the study and were subjected to hematological assessment. Figure 1 shows the distribution of subjects according to outcome of hematological assessment.

\section{Normal patients}

Patients with normal iron profile as well as normal $\mathrm{Hb}$ electrophoretic pattern. Out of 407 subjects selected for the purpose of study, 375 (92.1\%) had IDA, $15(3.7 \%)$ were BTT, $5(1.2 \%)$ were positive for thalassemia major, $1(0.2 \%)$ for F-variant and $11(2.7 \%)$ were normal.

Mean MCV, RDW, \% RDW and S. TIBC levels of BTT patients was significantly lower as compared to IDA patients while mean hemoglobin level, S. Iron, S. Ferritin levels of BT'T patients was significantly higher (Figure 2) as compared to that of IDA patients $(\mathrm{p}<0.05)$. For all the other parameters, statistically, no significant difference between two groups was observed ( $p>0.05)$

Evaluation of Shine and Lal Index (Table 1) revealed the sensitivity, specificity, PPV, NPV, and accuracy to be $80 \%$, $23.7 \%, 4 \%, 96.7 \%$ and $25.9 \%$ respectively. On calculating the performance of the diagnostic test using Youden'J statistic, it was found to be only $3.7 \%$.

Evaluation of Mentzer Index (Table 2) revealed the sensitivity, specificity, PPV, NPV, and accuracy to be $46.7 \%$, $97.6 \%, 43.8 \%, 97.8 \% \& 95.6 \%$ respectively. On evaluating the performance of test by calculating Youden's J statistic, it was observed to be having a performance level of $44.3 \%$.

\section{DISCUSSION}

The two most important causes of microcytic anemia are IDA and $\beta$-thalassemia trait. ${ }^{16-18}$ Among the spectrum of $\beta$-thalassemia syndrome forms, BTT is the most common form encountered in India and is responsible for causing

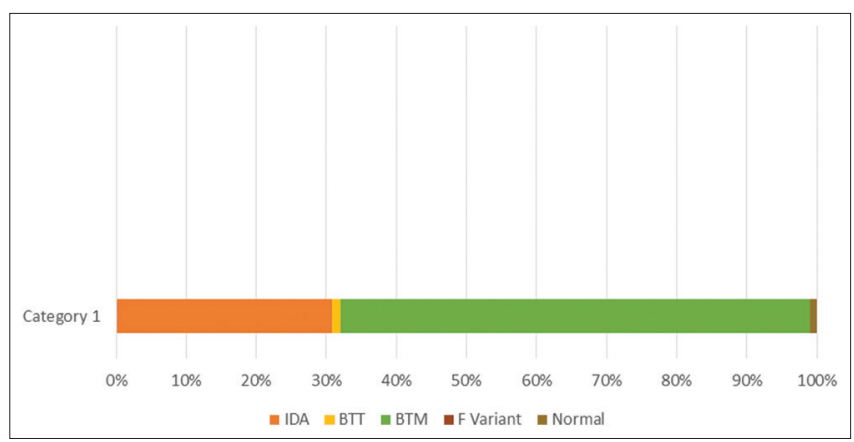

Figure 1: Distribution of patients according to outcome of hematological assessment anemia other than IDA. However, a traditional approach followed by most general practitioners and blood bank physicians is a trial of iron treatment whenever anemia and/or microcytosis are encountered. ${ }^{17}$ however this approach leads to unnecessary iron therapy/iron overload leading to oxidative stresses which leads to deterioration of patient instead of providing a cure. One of the reasons for adaptation of this approach is that burden of BT'T is not exactly reported widely and at the same time the diagnosis of $\beta$-thalassemia is a cumbersome task which has both time as well as financial implications. ${ }^{19-20}$

In such a scenario, a hematologist is concerned about reducing the burden of cost and time in order to diagnose $\beta$-thalassemia. The present study is an attempt in this direction. Out of 407 subjects selected for the purpose of study, 375 (92.1\%) had IDA, 15 (3.7\%) were BT'T positive, 5 were positive for thalassemia major, $1(0.2 \%)$ for F-variant and $11(2.7 \%)$ were normal. The mechanism by which anemia occurs alters the RBCs indices in a predictable manner. MCV is considered as the most informative parameter and anemias can be categorized as microcytic (MCV $<78 \mathrm{fl}$ ), normocytic (MCV 80-90 fl), and macrocytic $(\mathrm{MCV}>100 \mathrm{fl})$. Both $\beta$-thalassemia carriers and IDA cause microcytic anemia. ${ }^{21}$

In past several attempts have been made to develop a discrimination index which is suitable for discrimination between IDA and BT'T. Some of these indices are-England and Fraser, ${ }^{22}$ Mentzer, ${ }^{14}$ Shine and Lal, ${ }^{13}$ Srivastava, ${ }^{23}$ Green and King, ${ }^{24}$ Ricer et al., ${ }^{25}$ and Red Cell distribution Width (RDW) (Jayabose et al.,1999), ${ }^{26}$ among many. In present study, we targeted two of these popular indices i.e., Shine and Lal and Mentzer indices for evaluation of their efficacy. The given table shows the efficacy of these indices evaluated in present study.

As shown in Table 3, between these two indices. Shine and Lal index $(80 \%)$ is much more sensitive than Mentzer Index $(46.7 \%)$. However, in terms of specificity Shine and Lal index is much less specific $(23.7 \%)$ in comparison to

$\begin{aligned} & \text { Table 1: Evaluation of sensitivity, specificity and } \\
& \text { efficiency of Shine and Lal index }(\mathbf{n = 4 0 7})\end{aligned}$
\begin{tabular}{lccc}
\hline Shine and Lal Index Values & BTT & IDA & Total \\
\hline$<1530$ & $15[\mathrm{TP}]$ & $292[\mathrm{FP}]$ & 307 \\
$>1530$ & $5[\mathrm{FN}]$ & $95[\mathrm{TN}]$ & 100 \\
Total & 20 & 387 & 407 \\
\hline
\end{tabular}

\begin{tabular}{|c|c|c|c|}
\hline Mentzer Index Values & BTT & IDA & Total \\
\hline$<13$ & 7 & 9 & 16 \\
\hline$>13$ & 8 & 366 & 374 \\
\hline
\end{tabular}


Mentzer Index (97.6\%). Thus indicating that the burden of evaluation using screening process is quite high for Shine and Lal index. To attain the level of sensitivity and specificity as indicated by these indices, the overburden of false positivity was quite high ranging from $96 \%$ (Shine and Lal Index) to $56.2 \%$ (Mentzer Index).

Different studies from across the world have evaluated the performance of hematologic indices and found them to provide variable efficacy in different environments.

The findings in Table 4 show the sensitivity of Shine and Lal index ranging from $83.1 \%$ to $100 \%$ as compared to $80 \%$ and specificity ranged from $29.62 \%$ to $100 \%$ as compared to $23.7 \%$. The positive predictive value of the test has been reported to be ranging from $41.8 \%$ to $100 \%$ in different series as compared to $4 \%$ whereas negative predictive value of the index has been reported to range from $3 \%$ to $100 \%$ in different series. The performance

\begin{tabular}{|c|c|c|c|c|c|c|}
\hline Index & Sensitivity & Specificity & PPV & NPV & Accuracy & $\begin{array}{l}\text { Youden's } \\
\text { Index }\end{array}$ \\
\hline $\begin{array}{l}\text { Shine } \\
\text { and Lal }\end{array}$ & 80 & 23.7 & 4 & 96.7 & 25.9 & 3.7 \\
\hline $\begin{array}{l}\text { Mentzer } \\
\text { Index }\end{array}$ & 46.7 & 97.6 & 43.8 & 97.8 & 95.6 & 44.3 \\
\hline
\end{tabular}

\begin{tabular}{|c|c|c|c|c|c|c|}
\hline $\begin{array}{l}\text { Study } \\
\text { (year) }\end{array}$ & $\begin{array}{c}\text { Total No. } \\
\text { (BTT) }\end{array}$ & Sensitivity & Specificity & PPV & NPV & $\begin{array}{l}\text { Youden's } \\
\text { Index }\end{array}$ \\
\hline $\begin{array}{l}\text { Sirdah } \\
\text { et al. } \\
\text { (1998) }\end{array}$ & 262 & 97.2 & 49.7 & 41.8 & 97.9 & 46.9 \\
\hline $\begin{array}{l}\text { Rathod } \\
\text { et al. } \\
\text { (2007) }\end{array}$ & 200 & 94.8 & 70 & - & - & 64.8 \\
\hline $\begin{array}{l}\text { Higgins } \\
\text { et al. } \\
(2007)\end{array}$ & 327 & 100 & 100 & 100 & 100 & 100 \\
\hline $\begin{array}{l}\text { Trivedi } \\
\text { and } \\
\text { Shah } \\
(2010)\end{array}$ & 216 & 99.25 & 29.62 & 88.88 & 44.8 & 28.87 \\
\hline $\begin{array}{l}\text { Rahim } \\
\text { and } \\
\text { Keikhaei } \\
(2009)\end{array}$ & 323 & 100 & 89 & 82 & 100 & 89 \\
\hline $\begin{array}{l}\text { Niazi } \\
\text { et al } \\
\text { (2010) }\end{array}$ & 312 & 72 & 100 & 100 & 3 & 72 \\
\hline $\begin{array}{l}\text { Aziz } \\
\text { et al } \\
\text { (2010) }\end{array}$ & 901 & 83.1 & 90.6 & 89.6 & 86.4 & 73.7 \\
\hline $\begin{array}{l}\text { Present } \\
\text { Study } \\
(2013)\end{array}$ & 390 & 80 & 23.7 & 4 & 96.7 & 3.7 \\
\hline
\end{tabular}

of the index ranged from $28.87 \%$ to $100 \%$. The poor performance of the index in present study might be attributed to very low prevalence of BTT positive patients in present study $(3.8 \%)$. The maximum efficacy $(100 \%)$ in a study by Higgins et al., ${ }^{27}$ might be attributed to high prevalence of BTT as well as the iron repleted status of the patients. In present study, no such replenishment was done. The findings in present study are close to that of Niazi et al., ${ }^{28}$ and Aziz et al., ${ }^{29}$ in terms of sensitivity, however, in terms of specificity they come close to the observations of Trivedi and Shah. ${ }^{30}$ It must be kept in mind that prevalence rates affect the sensitivity, specificity, positive predictive value and negative predictive value in an influential manner.

The extreme variability in results with respect to performance of test indicates that Shine and Lal index has a limited utility which is dependent on prevalence as well as guided by time and place of study thus indicating that the empiricity of the index is questionable.

In present study, Mentzer index did not perform well as compared to various studies quoted above (Figure 3). Apart from the fact that the present study was carried out in a low prevalence scenario, this might also be due to the fact that we had taken the designated cut-off of $<13$ for discrimination. One of the studies by Higgins et al., ${ }^{27}$ also

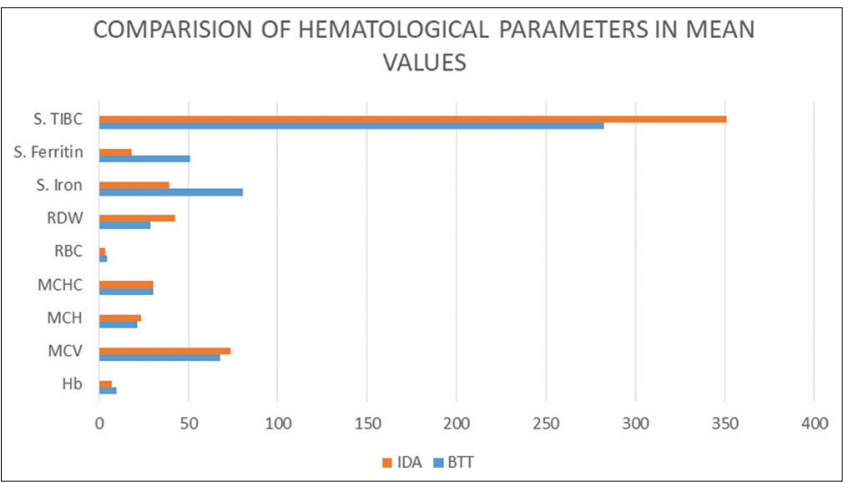

Figure 2: Comparison of hematological parameters between IDA and BTT subjects

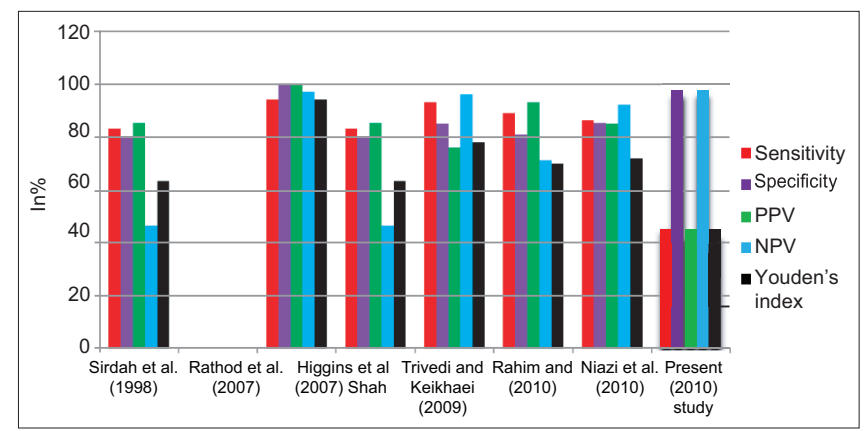

Figure 3: Shows a comparison of efficacy of Mentzer Index observed by different workers

Asian Journal of Medical Sciences | Oct 2021 | Vol 12 | Issue 10 
used a modified prevalence scenario, relaxing the criteria for selection will have a very low impact on the specificity, however, it may increase the sensitivity substantially for this purpose. We performed a receiver-operator curve analysis to achieve a better cut-off which might have adequate sensitivity.

From the point of view of screening ability, the present study could not find any single index to be having adequate sensitivity as well as specificity, even the indices seeming to be promising carried a burden of high false positivity, thus rendering the purpose of screening to reduce the burden of overall final assessment and losing its practical use as a final test, though tests like Mentzer index were highly specific $(97.6 \%)$ yet they had sensitivity level of $46.7 \%$ only.

Our study was peculiar from the point of view that it tested the efficacy of the test in a real life situation i.e., in a low prevalence setting, and the evaluation of the efficacy of different scales showed that the performance is grossly dependent on the prevalence scenario. The studies showing $100 \%$ performance of some indices are sample specific that have derived sample specific cut-off values which fail to stand the test of empiricity. However, the present study which was done in a real life simulation scenario had a high impact on the performance level owing to chance error. In present study, a chance false negative result affected the sensitivity by $6.7 \%$, however in a purposively laid sampling design this error is reduced to as low as $0.6 \%{ }^{27}$

Despite being well accepted, the emergence of newer scales from time to time and testing-retesting of these indices shows that all the tests have their limitations which are felt during practical use but in a purposive sampling design these errors get suppressed and unrealistic performance levels of different tests are achieved.

Keeping in view the findings observed in present study, we would like to recommend testing of these indices for their empiricity by carrying out the performance of different indices in real-life situation rather than laying a biased purposive sampling design.

\section{CONCLUSION}

We hereby conclude that no single Discrimination Index can be applied to screen IDA from BTT, and application of multiple indices shall increase the sensitivity and specificity of the screening process. Our study was a prospective one and of a short duration yielding smaller number of BT'T cases in a low prevalence zone of thalassemia. Further studies of sensitivity and specificity of many discrimination indices on a larger sample may yield some conclusive results.

\section{REFERENCES}

1. de Benoist Bruno, McLean Erin, Egli I,Cogswell M (Eds.). Worldwide Prevalence of Anaemia 1993- 2005. WHO Global database on anaemia, WHO, Geneva, 2005

2. Iron deficiency anaemia: Assessment, prevention, and control. A guide for programme managers. Geneva, World Health Organization, 2001 (WHO/NHD/01.3).

3. Aessopos A, Kati M and Farmakis D. Heart disease in thalassemia intermedia: a review of the underlying pathophysiology. Haematologica. 2007; 92(5): 658-665.

https://doi.org/10.3324/haematol.10915

4. Ataga KI, Cappellini MD and RachmilewitzEA. Beta-thalassaemia and sickle cell anaemia as paradigms of hypercoagulability. $\mathrm{Br} \mathrm{J}$ Haematol. 2007; 139(1): 3-13.

https://doi.org/10.1111/j.1365-2141.2007.06740.x

5. Barton JC. Chelation therapy for iron overload. Curr Gastroenterol Rep. 2007; 9(1): 74-82.

https://doi.org/10.1007/s11894-008-0024-9

6. Efremov GD. Dominantly Inherited beta-Thalassemia. Hemoglobin.2007; 31(2): 193-207.

https://doi.org/10.1080/03630260701290092

7. Ghosh K and Ghosh K. Pathogenesis of anemia in malaria: a concise review. Parasitol Res. 2007; 101(6): 1463-1469.

https://doi.org/10.1007/s00436-007-0742-1

8. Quek L and Thein SL. Molecular therapies in beta-thalassaemia. Br J Haematol. 2007; 136(3): 353-365.

https://doi.org/10.1111/j.1365-2141.2006.06408.x

9. Theodorsson E, Birgens $\mathrm{H}$ and Hagve TA. Haemoglobinopathies and glucose-6-phosphate dehydrogenase deficiency in a Scandinavian perspective. Scandinavian J Clin Lab Invest. 2007; 67(1): 3-10.

https://doi.org/10.1080/00365510601046359

10. Angastiniotis $M$ and Modell B. Global epidemiology of hemoglobin disorders. Ann N Y Acad Sci. 1998 30; 850: 251-269.

https://doi.org/10.1111/j.1749-6632.1998.tb10482.x

11. Bunn HF. Hemoglobin: Molecular, Genetic and Clinical Aspects W.B. Saunders Company 1984.

12. Gottfried EL. Erythrocyte indexes with the electronic counter. N Engl J Med. 1979;300:1277. https://doi.org/10.1056/NEJM197905313002219

13. Shine I and Lal S. A strategy to detect beta-thalassaemia minor. Lancet. 1977;1(8013):692-694. https://doi.org/10.1016/S0140-6736(77)92128-6

14. Mentzer WC. Differentiation of iron deficiency from thalassaemia trait. Lancet. 1973;1(7808):882. https://doi.org/10.1016/S0140-6736(73)91446-3

15. Klee GG, Fairbanks VF, Pierre RV, Virgh D and O'Sullivan MB. Routine erythrocyte measurements in diagnosis of iron deficiency anemia and thalassemia minor. Am J Clin Pathol.1976; 66(5):870-877.

https://doi.org/10.1093/ajcp/66.5.870

16. Oski FA. Iron deficiency in infancy and childhood. N Engl J Med. 1993; 329:190-193. https://doi.org/10.1056/NEJM199307153290308

17. Sukumaran PK. Abnormal hemoglobins in India. In: Sen NN, Basu AK eds. Trends in Hematology. Calcutta: Saraswati Press. 1975. pp. 225-236.

18. Wharton BA. Iron deficiency in children: detection and prevention. Br J Haematol. 1999;106(2):270-280. 
https://doi.org/10.1046/j.1365-2141.1999.01511.x

19. Weatherall DJ and Clegg JB. The Thalassemia Syndromes. 4 th ed. Oxford, London, Edinburgh, Boston, Melbourne: Blackwell Scientific Publications; 2001.

20. Crosby WH. Letter to the Editor. Blood. 1972; 39:298. https://doi.org/10.1182/blood.V39.2.298.298

21. Gorakshakar AC and Colah RB. Is RBC discrimination index suitable for differentiating $\alpha$ - and $\beta$ - thalassemias? Indian $\mathrm{J}$ Hum Genet.2011; 17(3)115-116. https://doi.org/10.4103/0971-6866.92079

22. England JM and Fraser P. Discrimination between iron-deficiency and heterozygous- thalassemia syndromes in differential diagnosis of microcytosis. Lancet 1979; 1(8108):145-148. https://doi.org/10.1016/S0140-6736(79)90532-4

23. Srivastava $P C$ and Bevington JM. Iron deficiency and-or thalassemia trait. Lancet. 1973; 1(7807):832. https://doi.org/10.1016/S0140-6736(73)90637-5

24. Green R and King R. A new red blood cell discriminant incorporating volume dispersion for differentiating iron deficiency anemia from thalassemias minor. Blood Cells. 1989;15(3):481-495.
25. Ricerca BM, Storti S, d'Onofrio G, Mancini S, Vittori M, Campisi S, et al. Differentiation of iron deficiency from thalassemia trait: a new approach. Hematologica. 1987;72(5):409-413.

26. Jayabose S, Giavanelli J, Levendoglu-Tugal O, Sandoval C, Ozkaynak $F$ and Visintainer P. Differentiating iron deficiency index. J Pediatr Hematol. 1999: 21: 314. https://doi.org/10.1097/00043426-199907000-00040

27. Higgins $T$, Brierley $Y$ and Khanjuria $A$. Use of mathematical indices based on CBC data to identify patients with beta thlassemia minor. Revista Romana de Medicina de Laborator 2007;8(3): 7-12.

28. Niazi M, Tahir M, Razie FE and Hameed A. Usefulness of red cell indices in differentiating microcytic hypochromic anemias. Gomal J Med Sc. 2010; 8(2): 125-129.

29. Aziz B, Abolg hasem P and Reza E. Discrimination of betathalassemia minor and iron deficiency anemia by screening test for red blood cell indices. Turk J Med Sci. 2012; 42(2): 275-280.

30. Trivedi DP and Shah HA. Discriminant Functions In Distinguishing Beta Thalassemia Trait and Iron Deficiency Anemia: The value of the RDW-SD. The Internet Journal Of Hematology.2010;7: https://doi.org/10.5580/1b99

\section{Author's contributions:}

SA- Concept and design of study, Statistical analysis, Manuscript preparation; NZ- Literature review, Final manuscript preparation; SRM- Concept, Coordination, Review of literature; SI- Interpretation of result, Manuscript preparation; SA- Acquisition of data, review of literature.

\section{Work attributed to:}

Department of Pathology, Eras Lucknow Medical College and Hospital, Lucknow.

Orcid ID:

Dr. Noorin Zaidi- (1) http://orcid.org/0000-0003-3182-4777

Dr. Sumaiya Irfan- (1) https://orcid.org/0000-0001-7994-4132

Dr. Sharique Ahmad- (D) https://orcid.org/0000-0002-9637-8838 